\title{
A Elitização da Linguagem Jurídica e a Necessidade de sua Simplificação ${ }^{1}$
}

\author{
The Elitism of Legal Language and the NeEd of Simplification
}

\author{
Antonio Escandiel de Souza* \\ Carla Rosane da Silva Tavares Alves** \\ Tiago Anderson Brutti***
}

Resumo: Este artigo apresenta resultados parciais do projeto $A$ simplificaşão da linguagem jurídica: um estudo sobre a visão da comunidade acadêmica da Universidade de Cruz. Alta. Mediante consulta e análise da percepção de alunos e de professores do curso de Direito, a investigação, de cunho qualitativo, discute a importância da simplificação da linguagem jurídica como uma das formas de democratizar ou de pluralizar o acesso ao Poder Judiciário, e, por suposto, de assegurar a justiça no caso concreto. Numerosas expressões jurídicas tradicionais persistem tendo seus significados incompreendidos pelos leigos e, também, em parte, pelos profissionais das diversas carreiras jurídicas, situação esta que, seguramente, desfavorece um acesso mais amplo à Justiça. Nesse cenário, a sociedade, de um lado, permanece, no geral, com suas

\footnotetext{
* Doutor em Linguística Aplicada pela Universidade Federal do Rio Grande do Sul UFRGS (2009). Professor Doutor Adjunto II na Universidade de Cruz Alta UNICRUZ.Contato: asouza@unicruz.edu.br.

** Doutora em Letras pela Universidade Federal do Rio Grande do Sul - UFRGS (2007). Professor Doutor Adjunto II na Universidade de Cruz Alta - UNICRUZ. Contato: ctavares@unicruz.edu.br.

*** Doutor em Educação nas Ciências pela Universidade Regional do Noroeste do Estado do Rio Grande do Sul - UNIJUÍ (2014). Professor Doutor Adjunto I na Universidade de Cruz Alta - UNICRUZ. Contato: tbrutti @unicruz.edu.br.

${ }^{1}$ O projeto de pesquisa intitulado "A simplificação da linguagem jurídica: um estudo sobre a visão da comunidade acadêmica da Universidade de Cruz Alta" é financiado pela Fundação de Amparo à Pesquisa do Rio Grande do Sul (FAPERGS).
} 
significativas dificuldades de compreensão, enquanto os cientistas ou práticos do Direito cultuam expressões da antiguidade ou do medievo, mantendo um indisfarçável distanciamento da linguagem coloquial. Advoga-se, aqui, que a sociedade não tenha o acesso ao Judiciário obstaculizado em razão da elitização do vocabulário jurídico tradicional. Os resultados preliminares da pesquisa sugerem que a simplificação da linguagem jurídica configura-se como fundamental para a democratização do acesso à Justiça.

Palavras-chave: Simplificação. Entendimento. Direito.

Abstract: This article presents the results of the research project entitled "Simplification of legal language: a study on the view of the academic community of the University of Cruz Alta". It is a qualitative nature study on simplifying the legal language as a means of democratizing/pluralize access to justice, in the view of scholars and Law Course teachers. There is great difficulty by society in the understanding of legal terms, which hinders access to justice. Similarly, the legal field is not far, of their traditional formalities, which indicates the existence of a parallel where, on one hand, is society, with its problems of understanding, and the other the law, its inherent and intrinsic procedures. However, the company may not have access to the judiciary hampered on account of formalities arising from the law and its flowery language. Preliminary results indicate simplification of legal language as essential to real democratization of access to Law/Justice

Keywords: Simplification. Understanding. Law.

\section{Introdução}

Ao analisar a historicidade do fenômeno do Direito, tanto como inovação sociocultural quanto como ciência histórico-hermenêutica, observa-se que as expressões jurídicas vêm se constituindo em um saber elitizado, ou seja, privilegiado e para poucos. Em outras palavras, verifica-se que vem sendo construído um repertório jurídico acessado por alguns e ininteligível para muitos, o que acarreta um grande distanciamento entre a sociedade civil e o próprio campo dos profissionais do Direito. 
Diante dessa linguagem inacessível, muitos indivíduos acabam desacreditando no Poder Judiciário. Clama-se, há muito tempo, por uma simplificação do "juridiquês", linguagem que consiste no emprego de vocábulos de difícil compreensão a fim de elitizar a linguagem jurídica. Advoga-se, nesta pesquisa, que não é defensável a utilização de termos e de concepções de complexo entendimento até mesmo para advogados e, inclusive, para juristas com pouca experiência e restrito contato com a norma considerada mais culta.

É, pois, com esse desafio no horizonte, que o projeto $A$ simplificação da linguagem jurídica: um estudo sobre a visão da comunidade acadêmica da Universidade de Cruz. Alta realiza um estudo crítico-reflexivo a respeito da simplificação da linguagem jurídica como forma de democratizar ou de pluralizar o acesso ao Direito/Justiça. A pesquisa, de cunho qualitativo e caráter empíricobibliográfico, almeja dar visibilidade aos resultados alcançados mediante consulta e análise da percepção de alunos e de professores do curso de Direito.

Delinearam-se, para a pesquisa, os seguintes objetivos específicos: a) fomentar a discussão sobre a simplificação da linguagem jurídica na comunidade acadêmica; b) analisar a percepção dos estudantes e professores do curso de Direito sobre a linguagem jurídica, o acesso à Justiça e a compreensão acerca do Direito e da justiça; c) evidenciar a relevância da temática para os futuros operadores do Direito; d) conscientizar a comunidade acadêmica sobre a importância da simplificação da linguagem jurídica, para uma real democratização do Direito e da aplicação da justiça; e) incitar a reflexão sobre o uso abusivo de termos e de expressões rebuscadas, as quais podem prejudicar a compreensão do que é o Direito e de como essa linguagem pode afetar o acesso à Justiça; e f) contribuir, através da divulgação dos resultados obtidos, para futuras pesquisas.

Vale ressaltar que a ideia de realizar a pesquisa emergiu de discussões avivadas no âmbito da disciplina "Competência Comunicativa", a qual compõe a grade curricular do quinto semestre do curso de Direito da Universidade de Cruz Alta. Muitos estudantes manifestaram interesse e reconheceram a necessidade de uma abordagem mais efetiva dessa temática durante o processo de formação acadêmica. Buscou-se, portanto, acima de tudo, contemplar um anseio da comunidade acadêmica da Universidade, 
provocando reflexões acerca da relevância da acessibilidade e da inteligibilidade da linguagem jurídica entre os atores sociais, linguagem que democratiza o conhecimento do Direito e aproxima os sujeitos das estruturas e dos mecanismos de realização da justiça.

\section{A Linguagem e o Discurso no Horizonte do Direito}

A linguagem é o medium da compreensão humana, sentencia Gadamer (2010). Ela é, por assim dizer, “a casa do ser" que habitamos, imprescindível para as interações entre os indivíduos em sociedade. Ressalte-se que a "essência" da linguagem comporta igualmente uma inconsciência abissal dela. Com efeito, só podemos pensar dentro de uma linguagem, mas o fato de que nosso pensamento habita a linguagem constitui o enigma mais profundo que a linguagem propõe ao pensar.

A linguagem, de acordo com Gadamer (2010), não deve ser equiparada a um instrumento ou ferramenta, isso porque em todo o conhecimento de nós mesmos e do mundo sempre já fomos tomados pela nossa própria linguagem, que sempre já nos ultrapassou. Um vestígio de nossa finitude pode ser encontrado, segundo o filósofo, no fato de que em todos os nossos pensamentos e conhecimentos sempre já fomos precedidos pela interpretação do mundo feita na linguagem. Daí que a consciência do indivíduo não constitui um parâmetro para medir o ser da linguagem, caracterizado pela ausência de um eu e pela pertença à esfera do nós, tanto que quem fala uma língua por ninguém mais compreendida simplesmente não fala, justamente porque falar significa falar a alguém e ser compreendido.

Cada grupo social expressa sua própria língua, com variações cuja origem se deve ao contexto histórico-cultural ou, ainda, às condições geográficas e econômicas. Logo, a linguagem de um povo não deve ser reduzida à condição de um mero instrumento de comunicação. Ela se apresenta, isso sim, como elemento identitário, não devendo servir como fator de exclusão social.

É importante distinguir a linguagem simbólica da linguagem conceitual. A primeira, segundo Castro (2010), funciona por analogias e por metáforas, realizando-se como imaginário social. Ela é inerente, por assim dizer, aos mitos, à religião, à poesia, ao romance, ao teatro, à emoção, à afetividade, à 
memória e à imaginação, podendo instituir, ao focalizar um futuro ou passado possíveis, um outro mundo análogo ao mundo real. Já a linguagem conceitual é inerente à filosofia e às ciências, evitando a analogia e as metáforas, bem como o uso de palavras carregadas de múltiplos sentidos. Procura, inclusive, convencer e persuadir por meio de argumentos, raciocínios e provas, buscando definir o real com a intenção de decifrá-lo e de superar as aparências. Esta é a linguagem adotada na esfera jurídica, já que a própria estrutura do discurso judicial determina o uso da linguagem conceitual.

O século passado nos presenteou com a fundação e o desenvolvimento de duas ciências da linguagem: a Linguística, ciência da linguagem verbal, e a Semiótica, ciência de toda e qualquer linguagem. O objeto de cada uma delas é diagnosticar que existe a linguagem verbal, veículo de conceitos e articulada no aparelho fonador, e que, sobretudo no Ocidente, desenvolveuse uma tradução visual alfabética chamada "linguagem escrita", ao mesmo tempo em que se reconhece a existência de múltiplas outras linguagens que traduzem sistemas sociais e históricos de representação do mundo. Costa (2003) assevera que todo cuidado é pouco ao se falar em linguagem, pois melhor seria referir-se a "linguagens".

Como acontece em qualquer espaço de poder, o acesso a esse universo não é franqueado a qualquer um. Por ter consciência da importância do grupo de que fazem parte, aqueles que detêm o privilégio de pertencerem ao mundo jurídico fazem de tudo para que esse mundo sagrado não seja profanado pela presença dos não iniciados. De acordo com Carvalho (2006), na promoção dessa separação fundamental entre quem faz e quem não faz parte do mundo jurídico, entra em ação um conjunto de elementos, que são tão mais eficazes quanto menos são percebidos como aparatos de segregação.

Assim, ainda consoante o aludido autor, o uso de vestes talares nos tribunais, as formalidades excessivas dos ritos judiciários, o tratamento de doutor - exigência obrigatória para se dirigir a qualquer membro do universo jurídico -, entre outros elementos, atuam em conjunto para reforçar sempre a ideia de que o mundo do Direito é mesmo uma realidade à parte em relação ao resto da sociedade. Além do mais, e principalmente, esses elementos contribuem de forma significativa para criar uma barreira entre o contexto do Direito e o das pessoas "comuns", em termos de acessibilidade a uma digna prestação jurisdicional. 
Na opinião de Carvalho (2006), é nesse processo de violência simbólica - que "protege" parte da população do acesso ao ambiente jurídico - que a linguagem jurídica apresenta toda sua eficácia. Trata-se de uma maneira específica com a qual magistrados, advogados, promotores e outros profissionais do Direito têm utilizado a linguagem e que, a despeito de qualquer argumento a favor, mais tem servido para negar o acesso ao universo jurídico à maioria dos cidadãos brasileiros.

É interessante compreender, em conformidade com Costa (2003, p. 15), que a literatura jurídica tem conferido especial relevância à comunicação verbal, predileção que se explica nas raízes históricas dos sistemas judiciários ocidentais, cada vez mais complexos pela necessidade de regulamentação dos comportamentos dos indivíduos e da atuação do Estado. É do sistema românico (Civil law), sempre devoto extraordinário da lei escrita, o culto à codificação para que "a ninguém seja lícito ignorar a lei”. A escola anglosaxônica (Common law) substituiu o apego à lei pela figura do julgador. É possível que daí decorra, entre nós, os latinos, o sentimento de que um instituto jurídico ganha solidez apenas quando normatizado em lei, pois só "vale o que está escrito". A um cidadão inglês, de outro modo, talvez mais importe saber qual é o entendimento de um juiz ou tribunal sobre determinada questão jurídica em dado momento e espaço.

Foucault (2010) apresenta a instância do discurso jurídico enquanto resultado de diversos sistemas de controle da palavra, resultado das mais diversas práticas restritivas da palavra: sejam aquelas que limitam o que pode ser dito de verdadeiro ou o que pode ser dito de razoável, operando como uma espécie de bloqueio; sejam aqueles mecanismos que prendem tudo aquilo que aparece na ordem do discurso a um mesmo texto primeiro, autor e disciplinas; sejam aqueles que, pela instituição de uma cena a repetir, pela constituição de "sociedades de discurso", pelo funcionamento doutrinal do discurso, pelas apropriações sociais, limitam os sujeitos falantes. São três os sistemas de exclusão do discurso: externos - o interdito, a partilha da razão e da loucura e a vontade de verdade; internos - o comentário, o autor, as disciplinas teóricas; exclusão dos sujeitos falantes - rituais da palavra, sociedades de discurso, doutrinas e apropriações sociais. Em outras palavras, aquilo que é efetivamente dito não provém de um tesouro infinito de significações, mas de condições de possibilidade. 
Logo, a compreensão do poder discursivo, segundo Foucault (2010), não é equiparável a um fenômeno de dominação maciço e homogêneo de um indivíduo, grupo ou classe sobre outros, mas como algo que circula e só funciona em cadeia, exercendo-se em rede. Não é algo unitário e global, senão que apresenta formas heterogêneas, em constante transformação. Não se trata de uma coisa em si, mas sim de um conjunto de práticas sociais que pressupõe relações em diversos pontos e lugares da rede social.

Dessa forma, para que o discurso jurídico possa assumir um papel revolucionário, deve contar com a ação reivindicatória das pessoas que, se percebendo responsáveis por essa construção, não abdicam de seus direitos, induzindo, nessa correlação de forças sociais, a sua "participação decisória", autônoma e cidadã. O poder se exerce independente de sua vinculação com o Estado, e sua dinâmica está ancorada em "efeitos de verdade" que ele procura produzir no interior dos discursos. Foucault (2010, p. 16) acentua que "a verdade deve ser compreendida como um sistema de procedimentos ordenados para a produção, regulamentação, distribuição, circulação e operação de enunciados".

Nesse enfoque, Foucault (2010) revela que o discurso não é somente aquilo que traduz as lutas dos sistemas de dominação, mas é a coisa pela qual, por meio da qual e através da qual se luta; o discurso é o poder a ser tomado. Desenvolver a simplicidade é uma das formas de assegurar a existência individual do homem e também de legitimar o Direito.

Isto porque as normas jurídicas não são entes independentes dos agentes sociais, uma vez que são reflexos dos movimentos destes. Ao isolar as normas, busca-se construir uma impressão de que elas poderão existir para sempre, independente da pressão social: essa é a ideologia que prega a manutenção do status quo. O Direito procura construir, destaca Campello (2009), uma simbologia própria para a utilização de operadores "aptos" e "treinados" para tanto, ou seja, para controlar e manter dentro das expectativas do aceitável os potenciais conflitos sociais que possam emergir das diversas interações entre os agentes socais.

Nota-se que o Direito cria um discurso, sustentado na forma, a fim de limitar não somente a atuação dos agentes sociais, mas a própria interpretação das normas jurídicas. Então, para conseguir manter a eficácia dessas regras, faz-se necessária a adesão daqueles que irão suportar tal "carga", 
e isso se concretiza pela perda do discernimento dos destinatários das normas, os quais estão sob prescrições arbitrárias, não estando aptos a questioná-las ou delas discordar, como aponta Santana (2012).

O estudo da comunicação no sistema judiciário brasileiro tem, assim, privilegiado o enfoque da escrita em detrimento da oralidade, razão pela qual muitos "operadores do Direito" foram "doutrinados" desde os bancos acadêmicos a acreditar que "o que não está nos autos não está no mundo", assinala Santana (2012). A atividade jurisdicional se reduziu, portanto, a um processo de comunicação quase exclusivamente escrita: juízes, advogados, promotores e escrivães usam quase que exclusivamente o meio de comunicação da escrita. Mesmo as reclamações trabalhistas e os depoimentos de partes e testemunhas precisam se converter à linguagem escrita. Os tribunais valorizam mais a documentação dos julgados, reduzidos quase sempre na linguagem escrita.

Sobre tal ponto, Costa (2003) destaca a noção segundo a qual, embora a comunicação não verbal tenha despertado pouco interesse dos estudiosos da linguagem jurídica, não se nega sua existência no "modo jurídico brasileiro", cuja relevância algumas vezes reflete nas linguagens escrita e falada. A linguagem do sistema judiciário nacional chega a confundir-se em alguns aspectos com a linguagem das religiões. O caráter esotérico de ambas as linguagens também as aproxima no sentido de que supostamente tratam de um saber que não pode ou não deve ser vulgarizado e que é restrito a iniciados.

Particularmente, entre os ocidentais, ainda de acordo com Costa (2003), muitos sinais (signos) religiosos migraram para a liturgia forense sem qualquer dificuldade, ainda que a separação dos poderes temporal e religioso tenha sido aclamada como uma das maiores conquistas da democracia moderna. São frequentemente tomados como ícones de ambas as dimensões balanças e espadas empunhadas por estátuas de feições angelicais. Trata-se de versões profanas dos arquétipos de virtude das divindades greco-romanas. O significante, em ambas, igualmente coincide: a crença na igualdade entre os sujeitos e em um sentimento de justiça acima deles. A justiça impõe o signo da divindade para realçar seu poder.

Um segundo elemento marcante da comunicação não verbal no Judiciário é o rigor indumentário. Costa (2003) ressalta que, talvez, apenas as religiões tradicionais sejam comparáveis aos rigores dos paramentos dos 
rituais forenses. Para ele, um sacerdote e um juiz em suas vestimentas se confundem (a veste talar cria um "ar" de superioridade). Por último, um importante traço dessa comunicação é a linguagem corporal. A comunicação gestual na instituição também parece fincar raízes em posturas monásticas que aderem inconscientemente à figura do magistrado e de seus auxiliares. A sisudez da deusa Themis parece encarnar no magistrado, tornando-o a semelhança de outras referências da cultura judaico-cristã. Não por acaso, a divindade, nessa cultura, é sempre representada, dentre outros papéis, como um julgador que não sorri e não chora; enfim, que jamais exterioriza o menor traço de emoção.

A linguagem verbal judiciária está marcada por uma espécie de cientificismo exacerbado, o que, a bem da verdade, não destoa de outros conhecimentos, como a Medicina, a Filosofia e a Economia. Santana (2012) declara que uma primeira característica desta linguagem é a ambiguidade. É difícil encontrar, no linguajar jurídico, um simples vocábulo que denote um único sentido. Para começar, poucos textos contêm mais ambiguidades que as leis, nas quais o risco dos casuísmos precisa ser contornado pelo uso de palavras e de expressões vagas que serão lidas de acordo com cada intérprete em seu tempo.

A tradição, por sua vez, é a segunda forte característica da linguagem verbal jurídica. A ambiguidade traz em si o inconformismo do intérprete a enriquecer a linguagem; a tradição se presta como freio à força criativa. Por aí se explica que muito do que se fala e se escreve na literatura jurídica e forense seja mera repetição de fórmulas e estilos que comprometem, e, no mais das vezes, bloqueiam o processo de comunicação. Santana (2012) acentua que o chamado "estágio obrigatório" nos cursos de graduação às vezes corresponde a um simples aprendizado por mimetismo, mera reprodução literal de exemplos de petições erigidos como modelos perfeitos e acabados. A didática da imitação da linguagem se entranha tanto que o futuro advogado, juiz, promotor ou escrivão sentirá dificuldade em escrever ou falar sem recorrer a latinismos e a fórmulas gongóricas.

Ao abordar o discurso jurídico, Sytia (2002) argumenta que a linguagem jurídica, entendida como mediadora entre o poder social e as pessoas, deveria expressar com fidelidade os exemplos de comportamento a serem seguidos, evitando-se ambiguidades e expressões que dificultem a aplicação da justiça. 
A linguagem jurídica deve, portanto, ser reconhecida como auxiliar na compreensão da lei e, também, como facilitadora da comunicação jurídica. Nessa direção, Sytia (2002) defende o ponto de vista segundo o qual a palavra, no contexto jurídico, deve ser empregada de forma clara e concisa, evitandose sutilezas semânticas e dubiedades na interpretação e na aplicação das leis:

... o estudante de Direito, bem como advogados, juízes e promotores, podem confundir, costumeiramente, o 'juridiquês' abusivo com a linguagem jurídica prática, 'normal', a qual possui destinatários que não os 'operadores do Direito'; linguagem esta que precisa ser engajada em um contexto mais amplo da 'formação discursiva', da ideologia, da história, das relações de significado dentro de uma determinada estrutura social (SYTIA, 2002, p. 128).

As palavras da autora vêm ao encontro dos objetivos deste estudo, uma vez que evidencia a necessidade de uma discussão e, acima de tudo, de muita reflexão a respeito do uso abusivo do "juridiquês" na conjuntura jurídica, sobretudo entre os estudantes, futuros operadores do Direito.

\section{Resultados Parciais Sistematizados pelo Projeto}

O contexto jurídico emprega uma linguagem verbal em que predomina a cientificidade e o uso de palavras e expressões ambíguas. Esta é uma das características da linguagem jurídica. Segundo Santana (2012), o advogado é o primeiro intérprete da norma, logo, tem maior liberdade nesse ponto porque a melhor interpretação será aquela que beneficiar seu cliente. A ambiguidade interpretativa recai no julgador que, por sua vez, emite nova opinião da qual outras ambiguidades surgirão para motivar os recursos de quem saiu prejudicado com a nova interpretação.

Ao realizar um estudo acerca dos temas terminologia jurídica e exercício da cidadania, Pereira (2001) focalizou a compreensão dos termos jurídicos por pessoas não especialistas e sua relação com a cidadania. Através de uma investigação de campo, o pesquisador concluiu que os indivíduos, no geral, encontravam muita dificuldade para compreender termos jurídicos. Constatou-se que $80 \%$ dos entrevistados, de ambos os sexos e de diferentes 
faixas etárias e níveis de escolaridade, demonstraram uma compreensão nula ou insatisfatória em relação a termos jurídicos. O pesquisador revela que apenas $10 \%$ do contexto pesquisado responderam corretamente ao solicitado.

Com suporte nos pressupostos já examinados, esta investigação é, também, do tipo descritiva ou de campo. Partiu-se, para alcançar os objetivos propostos, de leituras bibliográficas que fundamentaram a investigação. Estão ocorrendo encontros semanais com os participantes (coordenador do projeto, professores colaboradores e mestrando voluntário), a fim de estabelecer entre o grupo uma discussão teórica consistente, o que vem auxiliando na análise e na interpretação dos dados, bem como na organização e na divulgação dos resultados preliminares.

$\mathrm{Na}$ sequência, estão sendo aplicados questionários a estudantes e professores do curso de Direito, advogados ou não, da Universidade de Cruz Alta (UNICRUZ). De um universo de 500 estudantes matriculados, pretende-se entrevistar 30\%, no mínimo, visando a retratar a posição desses acadêmicos em relação à simplificação da linguagem jurídica como meio de acesso da população ao Direito e à justiça.

O questionário destinado aos acadêmicos, embora ainda não tenha sido aplicado, consiste nas seguintes perguntas:

1) Em suas aulas, no curso de Direito, há discussões sobre a simplificação da linguagem jurídica e suas implicações para a democratização do Direito/Justiça?;

2) Você encontra dificuldade em interpretar/compreender termos jurídicos? Justifique sua resposta;

3) Você conhece os significados dos termos em latim encontrados em manuais, legislação ou peça processual?;

4) Você considera necessário o uso de uma linguagem rebuscada no contexto jurídico? Justifique;

5) Como você vê a relação entre a sociedade e o Direito/Justiça, no que se refere ao processo de comunicação através da linguagem verbal?;

6) O que você pensa sobre a simplificação da linguagem jurídica como forma de democratização e acesso das pessoas à Justiça?

Quanto aos professores, de um universo de 20 profissionais atuando no curso, conseguiram-se realizar entrevistas com $20 \%$ deles. As entrevistas 
foram realizadas nos meses de setembro, outubro e novembro de 2014, sendo que o mês de dezembro de 2014 foi destinado às atividades de discussão dos resultados preliminares e à preparação dos estudos para divulgação. Pretende-se, ainda, entrevistar, no mínimo, 70\% dos professores atuantes no curso de Direito.

O questionário direcionado aos professores consistiu nas seguintes indagações:

1) Além de professor no curso de Direito, você exerce algum tipo de atividade da carreira jurídica?;

2) Você conhece todos os significados dos termos em latim encontrados em manuais, legislação ou peça processual?;

3) Você considera necessário o uso de uma linguagem rebuscada no contexto jurídico? Justifique;

4) Como você vê a relação entre a sociedade e o Direito/Justiça, no que se refere ao processo de comunicação através da linguagem verbal?;

5) O que você pensa sobre a simplificação da linguagem jurídica como forma de democratização e acesso das pessoas à Justiça?;

6) Durante as aulas você procura promover discussões/reflexões sobre a possível simplificação da linguagem jurídica e seus benefícios para a pluralização do Direito/Justiça?

Acerca do questionamento número um, verifica-se que poucos são os professores que têm na docência seu único emprego, lecionando, pesquisando e participando de atividades de ensino, pesquisa e extensão, embora alguns já tenham exercido, por longo período temporal, o cargo de servidor público estadual no Poder Judiciário. Entre os docentes, constatou-se que a maioria atua na profissão, como advogados, em seus escritórios próprios, ou como procuradores jurídicos nos municípios da região. Leciona no curso, inclusive, um Juiz de Direito do Estado na Comarca de Cruz Alta/RS.

Houve unanimidade quanto à questão número dois, pois todos afirmam a impossibilidade de, evidente e obviamente, conhecer todos os sentidos dos termos ou brocardos em latim encontrados na literatura jurídica e, muitas vezes, utilizados por profissionais da área, em razão da numerosa quantidade existente, de forma notória. No que tange ao uso da linguagem rebuscada - questão número três - a afirmação predominante, em que pese 
tenha havido divergência, foi a de que deve ser utilizada sem excesso, especialmente nos processos, pois o mundo jurídico tem uma linguagem própria que o caracteriza. Contudo, deveria ser mantida sempre uma coerência e uma simplicidade no discurso.

Destoando deste posicionamento, um docente entendeu que não deveria ser empregada, porém não deixou de registrar que toda área do conhecimento (seja Medicina, Odontologia, Contabilidade, Economia) possui uma linguagem com significados próprios, sendo que algumas palavras dizem respeito a cada área, o que não se faz de forma diferente no Direito. Afirmou que parcela desta linguagem se faz necessária, já que é da natureza desse ramo do saber, cabendo, no entanto, ao operador do Direito explicar ao seu cliente o significado do que está efetuando em termos de atuação profissional. $\mathrm{Na}$ mesma linha de raciocínio, outro docente compreendeu que o seu uso caracteriza um certo exibicionismo desnecessário e que não se mostra compatível com os modernos princípios processuais.

Outro docente enfatizou que poderia não considerar necessária, mas que também não consideraria descabido que, por vezes, a linguagem jurídica seja "rebuscada", que "escave" sua própria riqueza de sistematicidade, de especificidade e de historicidade. Considera que a linguagem jurídica deve ser precisa e não simplista. A simplificação da linguagem jurídica não deve implicar perda de complexidade. Sem embargo, considera uma excelente iniciativa discutir a possibilidade de tornar mais acessível aos leigos a linguagem jurídica consagrada secularmente na literatura da área.

Atinente ao questionamento número quatro, os professores reputaram que não é bom o processo de comunicação do mundo jurídico com a sociedade, tendo em vista que, mesmo sem o uso de linguagem rebuscada, existem vários termos jurídicos que possuem significados diferentes no trato jurídico, comparados ao uso comum. Além disso, muitos profissionais da área jurídica não são treinados no uso de uma linguagem verbal mais acessível à população em geral. Dessa forma, o povo desconhece muito a linguagem do Direito, o que resulta no fato de que o operador do Direito deve ter sensibilidade na hora de interagir com a sociedade, utilizando-se de uma linguagem acessível a todos e deixando a linguagem mais rebuscada para emprego no processo e frente aos membros do Judiciário. 
Observou-se, ainda, que cresce, a cada dia, a compreensão dos sujeitos sobre o sistema jurídico, principalmente diante do franqueamento das consultas on-line dos processos. Entretanto, ainda há um grande caminho de simplificação a ser percorrido. De igual modo, afirmou-se que, aos poucos, o "juridiquês" perde seu encanto. Avaliou-se que se vive uma época de desfetichização do Direito. Contudo, considerou-se que muitos institutos clássicos e termos de origem latina (ou oriundos de outras culturas, como a do Common law) são importantes para se poder expressar a especificidade da ciência jurídica.

Em relação à pergunta número cinco, os posicionamentos foram, em certa medida, discrepantes. Se a simplificação não significar perda de complexidade na compreensão do Direito, então não se consideraria descabido o esforço por tornar mais acessível e inteligível aos leigos a linguagem jurídica, favorecendo, com isso, por suposto, mais acesso à Justiça.

Outro entrevistado ressaltou a necessidade de simplificação, mas que, porém, ao operador do Direito caberia a importante tarefa de mediar essa linguagem com seu cliente. Segundo esse professor, não deveríamos esquecer que é da natureza de cada área possuir uma linguagem própria de comunicação. Seria essencial que parcela dessa linguagem permanecesse, sob pena de ocorrer uma excessiva relativização de conceitos. No mesmo viés, foi a concordância de um docente, pois seria indispensável se fazer entender, isso para que os cidadãos possam compreender o mundo jurídico e buscar seus direitos. Contudo, acredita que, no meio jurídico (entre os atores do mundo do Direito), deve ser mantida certa formalidade no processo, até mesmo como forma de manter as características originais das fontes do Direito.

Contrariamente, um professor visualizou que não entendia a existência de uma relação forte entre a linguagem jurídica e a democratização do acesso das pessoas à Justiça, por não ser necessário um maior ou menor conhecimento da linguagem jurídica para que as pessoas acessassem a Justiça, especialmente porque o acesso das pessoas ao Poder Judiciário não se dá, via de regra, de forma direta, mas sim com a intermediação de um advogado, de um defensor público, de um promotor público, por exceção, ou de um servidor judicial (quando reduzem a termo pedidos nos Juizados Especiais Cíveis em causas que impliquem uma quantia menor que vinte salários mínimos), os 
quais podem (e devem) esclarecer seus clientes ou representados quando uma utilização de linguagem rebuscada possa dificultar o conhecimento e o entendimento das leis ou das decisões judiciais, apesar de não terem sido treinados para tal.

E, por fim, quanto à indagação número seis, um professor alegou que essa tem sido uma discussão recorrente, por exemplo, nos encontros de disciplinas como Hermenêutica Jurídica, Filosofia Jurídica e História do Direito. Outro assegurou que procura expor os posicionamentos e as indagações perguntadas nesse questionário, tentando demonstrar que, principalmente na relação com o cliente, o uso de palavras difíceis em momento algum equivale a conhecimento e competência.

Um docente indicou que, de modo eventual, em aulas específicas, são abertos espaços de discussão, sendo que, paralelamente a isso, quando das exposições dos conteúdos, são trabalhados os signos e seus significados, capacitando o futuro profissional no atuar jurídico, ressaltando a sua importância como mediador dessa linguagem com o futuro cliente. Outro professor mencionou que, via de regra, não promove debates sobre essa questão com os alunos, salvo em uma ocasião em que foi trabalhado assunto referente à diferença da linguagem do meio jurídico se comparada à do meio jornalístico, aproveitando a existência de um programa preparado pela Associação de Juízes do Rio Grande do Sul.

Ante o exposto, compreende-se que foi atingido o principal objetivo proposto por esta investigação, que foi dar visibilidade a resultados parciais e preliminares alcançados pelo Projeto de Pesquisa $A$ simplificação da linguagem jurídica: um estudo sobre a visão da comunidade acadêmica da Universidade de Cruz. Alta. Concluiu-se, tal como asseverava Pinto (2005), que reconhecer a necessidade de simplificar a linguagem jurídica é já um primeiro passo para o revigoramento da democratização e da pluralização da Justiça. A simplificação da linguagem jurídica passa a ser um instrumento fundamental, tanto para os Juizados Especiais quanto para a Justiça Comum, ou tradicional, contribuindo em termos de promoção de maior acessibilidade ao Poder Judiciário, seja através de uma compreensão maior de sua organização e de sua atuação, seja através de uma maior inteligibilidade de sua linguagem específica entre os atores sociais. 


\section{Considerações Finais}

Uma das acepções do Direito o apresenta, por primazia, como um poder simbólico. Essa é a ótica de Lyra Filho (2006), para quem o Direito que controla a sociedade, moldando os rumos da história - é, sem dúvida, a forma por excelência do poder simbólico de nomeação que cria as coisas nomeadas e, em particular, os grupos; ele confere a estas realidades surgidas das suas operações de classificação toda a permanência, a das coisas, que uma instituição histórica é capaz de conferir a instituições históricas.

Bordieu (2007) é quem, por essa perspectiva, considera que o Direito é a forma, por excelência, do discurso atuante, capaz, por sua própria força, de produzir efeitos. Não seria demais afirmar que o Direito condiciona o mundo social, mas com a condição de não esquecer que ele próprio é consubstanciado por este.

Apesar de o discurso jurídico - como qualquer outro discurso científico, técnico ou profissional - possuir uma terminologia especializada, é fundamental atentar, como alerta Pereira (2001), para o fato de que as leis transitam entre universos distintos de usuários, devendo ser acessíveis a todos. Além disso, a compreensão de determinados termos jurídicos e de seu contexto é que torna possível, em princípio, o efetivo exercício da cidadania e do subsequente acesso à Justiça.

Sob essa perspectiva, em consonância com Santana (2012), muitas são as críticas em relação ao uso da linguagem jurídica ininteligível, especialmente ao verificar que a comunicação verbal no Judiciário tem sido estudada mais no que diz respeito a seus elementos de estilo do que na exata compreensão do fenômeno. É visível a preocupação na reformulação do discurso jurídico, ainda que muito mais voltada para o purismo gramatical do que propriamente à sua reestruturação ou simplificação. Algumas instituições de ensino superior, inclusive escolas preparatórias da carreira jurídica, têm dedicado um pouco de seus programas a cursos de reciclagem no português instrumental. A preocupação, contudo, se limita a isso.

Enquanto isso, perpetua-se a utilização desnecessária de uma linguagem rebuscada, repleta de termos, muitas vezes em latim, os quais dificultam o acesso à Justiça e ao conhecimento jurídico. Para que efetivamente ocorra a democratização e a pluralização da Justiça, torna-se imprescindível a 
simplificação da linguagem jurídica. Considerando que se trata de um tema polêmico e que vem sendo debatido há bastante tempo na sociedade, porém sem resultados consistentes, vislumbra-se ainda a carência de uma maior reflexão junto aos estudantes, futuros operadores do Direito, sobre o discurso jurídico, da linguagem jurídica inteligível e de sua relevância na democratização do acesso à justiça.

\section{Referências}

BOURDIEU, P. O poder simbólico. Rio de Janeiro: Bertrand Brasil, 2007.

CAMPELLO, A. E. B. B. O poder simbólico do Direito: uma introdução ao estudo do Direito pela obra de Pierre Bourdieu. Revista Praedicatio, São Luís, v. 1, p. 1-12, 2009.

CARVALHO, A. de. Linguagem jurídica: uma porta fechada para o acesso à Justiça. Correio Brą̧iliense, 27 mar. 2006. Disponível em: < http://bit.do/ cWBuU>. Acesso em: 03 jan. 2015.

CASTRO, L. A. de. Direito e linguagem. 31 mai. 2010. Disponível em: <http://bit.do/cWBvb>. Acesso em: 02 jan. 2015.

COSTA, M. D. A comunicação e o acesso à Justiça. Revista do Centro de Estudos Judiciários, Brasília, n. 22, p. 13-19, jul./set. 2003.

FOUCAULT, M. A ordem do discurso. 19. ed. São Paulo: Loyola, 2010.

GADAMER, H.-G. Verdade e método: complementos e índice. v. 2.

Tradução de Enio Paulo Giachini. Petrópolis: Vozes, 2010.

LYRA FILHO, R. O que é Direito. São Paulo: Brasiliense, 2006.

PEREIRA, M. H. A terminologia jurídica: óbice ao exercício da cidadania? 2001. Dissertação (Mestrado em Linguística) - Universidade Estadual Paulista Júlio de Mesquita Filho, São José do Rio Preto. 
PINTO, O. P. de A. M. Pela simplificação da linguagem jurídica: ninguém valoriza o que não entende. 2005. Disponível em: < http://bit.do/ cWBvt>. Acesso em: 03 jan. 2015.

SYTIA, C. V. M. O Direito e suas instâncias lingüisticas. Porto Alegre: Sérgio Fabris, 2002.

SANTANA, S. B. P. A linguagem jurídica como obstáculo ao acesso à Justiça: uma análise sobre o que é o Direito engajado na dialética social e a consequente desrazão de utilizar a linguagem jurídica como barreira entre a sociedade e o Direito/Justiça. Ambito Jurídico, Rio Grande, v. 15, n. 105, out. 2012. Disponível em: <http://bit.do/cWBvR>. Acesso em: 02 jan. 2015.

Recebido em: 07/04/2015

Aceito: 10/08/2015 